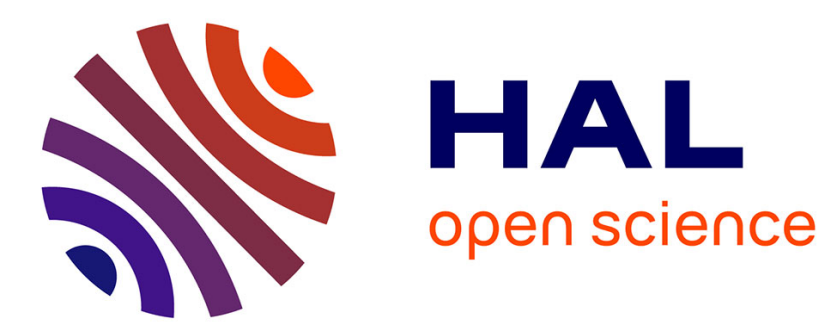

\title{
Quantum and Entertainment Computing
}

Nikitas M. Sgouros

\section{To cite this version:}

Nikitas M. Sgouros. Quantum and Entertainment Computing. 14th International Conference on Entertainment Computing (ICEC), Sep 2015, Trondheim, Norway. pp.575-577, 10.1007/978-3-31924589-8_60 . hal-01758444

\section{HAL Id: hal-01758444 \\ https://hal.inria.fr/hal-01758444}

Submitted on 4 Apr 2018

HAL is a multi-disciplinary open access archive for the deposit and dissemination of scientific research documents, whether they are published or not. The documents may come from teaching and research institutions in France or abroad, or from public or private research centers
L'archive ouverte pluridisciplinaire HAL, est destinée au dépôt et à la diffusion de documents scientifiques de niveau recherche, publiés ou non, émanant des établissements d'enseignement et de recherche français ou étrangers, des laboratoires publics ou privés. 


\title{
Quantum and Entertainment Computing
}

\author{
Nikitas M. Sgouros \\ Department of Digital Systems, University of Piraeus \\ 18534, Piraeus, Greece \\ sgouros@unipi.gr
}

\begin{abstract}
Quantum computing offers a radically different paradigm for dealing with information and its processing. This tutorial seeks to serve as a springboard that can inform and motivate entertainment computing researchers to delve into this new and exciting field and investigate novel ways for utilizing quantum-computational concepts in their work both from a theoretical and a practical point of view.
\end{abstract}

Keywords: Quantum Computing, Quantum Mechanics, Computational Methodologies for Entertainment, Theory and Practice of Entertainment.

\section{Introduction}

Quantum Computing seeks to develop a radically different paradigm for dealing with the character of information and its processing. This is because it is based on a set of rules governing the behavior of subatomic particles that is fundamentally different from the set of rules governing our everyday experience of the physical world. Contrary to the classical view, in the quantum world particles can be in multiple states at the same time, obey non-local constraints in their behavior, exhibit probabilistic behavior during observation and pose inherent limitations on the amount of knowledge we can have about them. What is more interesting in this case is that there exists a well-defined quantum theory able to accurately capture all the quirkiness of the quantum world. It is only recently that the implications of this theory for computation have become an active area of study and this has led to the development of abstract models for quantum computation with impressive potential. Another promising research area investigates the implications of this theory for the processing of knowledge and the roles it can play in addressing problems in the social sciences.

Entertainment Computing, on the other hand, seeks to develop computational models of entertainment, a task that is significantly complex due, among other reasons, to the difficulty in defining something as 'entertaining'. The problem stems from the fact that entertainment is primarily a phenomenological concept and as such it can be substantiated on an individual basis. Consequently, entertainment lacks the generality of objective properties and relies on subjectivity and context. It is for this reason that Quantum Computing provides an interesting alternative in capturing entertainment since it can deal with notions such as state, uncertainty, contextuality, subjectivity and transformation in completely new and unexplored ways. This tutorial seeks to provide an introduction to this new and exciting computing paradigm and 
explore the ways by which its models can provide possible building blocks for the theory and practice of entertainment computing.

\section{Objective \& Intended Audience}

The tutorial will seek to familiarize entertainment computing researchers with recent developments in quantum computing and investigate possible synergies between these two fields. The tutorial is oriented towards entertainment computing researchers with minimal exposure to quantum computing who wish to obtain an overview of the quantum field and try out prototype applications on the intersection between the quantum and the entertainment worlds.

\section{Content}

Although it might seem idiosyncratic to suggest that quantum theory that deals with the behavior of subatomic particles can be useful in thinking about computational forms of entertainment, we believe that there are very interesting insights to be gained from synergistic interactions between these two research areas. This tutorial will seek to describe in a simplified manner (by keeping the mathematical details to a minimum) the major features of quantum theory that can be relevant to this endeavor and provide references for further study. We will describe basic notions in quantum computing such as quantum state, superposition, entanglement, measurement, dynamics and algorithms. We will then turn our attention to specific examples of how these concepts can be used in the development of entertainment applications. We will present prototypes for games and narrative applications that incorporate elements of quantum behavior in their development and operation. The tutorial will conclude with a discussion of possible ways by which further synergies between quantum and entertainment computing can be pursued.

\section{Structure}

The tutorial will run for 4 hours. During the first half the participants will get familiarized with essential features of Quantum Mechanics and Quantum Computing. The second half will focus on outlining possible synergies between Quantum and Entertainment Computing and getting a hands-on experience with related applications in these fields. All the material for the tutorial will be available online after the event. The following table summarizes the tutorial structure.

\begin{tabular}{|l|l|}
\hline Time & Activity \\
\hline $8: 30-9: 15$ & Quantum Mechanics and its postulates \\
\hline 9:30-10:15 & Quantum Computing Essentials \\
\hline 10:30-11:15 & Drawing Synergies between Entertainment \\
\hline
\end{tabular}




\begin{tabular}{|l|l|}
\hline & and Quantum Computing \\
\hline $11: 30-12: 15$ & $\begin{array}{l}\text { Experimentation with Quantum } \\
\text { Computing Applications in Entertainment }\end{array}$ \\
\hline $12: 15-\ldots \ldots$ & Discussion \& Conclusions \\
\hline
\end{tabular}

\section{Organizer Details}

Nikitas M. Sgouros is a Professor in the Department of Digital Systems at the University of Piraeus, Greece working on Entertainment Computing, Multimedia Systems, Artificial Intelligence and Robotics. He has also been a Director of the M.Sc. in Digital Systems and a Deputy Director of this Department. Prof. Sgouros is the author of more than 60 publications in scientific journals and conferences. He holds a PhD in Computer Science from Northwestern University, USA (1994) a M.Sc. with distinction in Artificial Intelligence from the University of Edinburgh, UK (1990) and a Diploma in EECS from the National Technical University of Athens, Greece (1988).

Acknowledgements. Presentation of this tutorial was partially supported by the University of Piraeus Research Center.

\section{References}

1. Nielsen, M. A., Chuang, I. L., Quantum Computation and Quantum Information, Cambridge University Press (2010)

2. Mermin, N. D., Quantum Computer Science: An Introduction, Cambridge University Press (2007)

3. Yanofsky, N. S., Manucci, M. A., Quantum Computing for Computer Scientists, Cambridge University Press (2008)

4. Merzbacher, E., Quantum Mechanics, Wiley (1997)

5. Susskind, L., Friedman, A., Quantum Mechanics - The Theoretical Minimum, Basic Books (2014)

6. Busemeyer, J. R., Bruza, P. D., Quantum Models of Cognition, Cambridge University Press (2012)

7. Haven, E., Khrennikov, A., Quantum Social Science, Cambridge University Press (2013)

8. Goff, A., Quantum tic-tac-toe: A teaching metaphor for superposition in quantum mechanics, American Journal of Physics 74 (11), (2006)

9. Kitto, K., Boschetti, F., Attitudes, Ideologies and Self-Organization: Information Load Minimization in Multi-Agent Decision Making, Advances in Complex Systems Vol. 16, Nos. 2 \& 3, World Scientific Publishing Company (2013)

10. Griffiths, D. J., Introduction to Quantum Mechanics, Pearson Prentice Hall (2004) 